Tetiana Kolomiiets,

PhD (Candidate of Psychological Sciences), teaching assistant, Department of Social and Applied Psychology, Zhytomyr Ivan Franko State University, 40, Velyka Berdychivska Str., Zhytomyr, Ukraine

\title{
DEVELOPMENT OF EMPATHIC INTERPERSONAL INTERACTION IN ADOLESCENCE
}

The article is devoted to consideration of empathic interpersonal interaction as a particular form of implementation of human-centered relationships. The author's program of psychological assistance for the development of empathic interpersonal interaction in adolescence is presented. There have been theoretically grounded its structure (consisting of four blocks: "The development of empathy", "The development of different types of empathic interaction", "Reflection of one's own experience" and "Transferring of acquired knowledge, skills and abilities in real life") and methods (including mini lectures, demonstration of short films with pronounced empathogenic situation, video fixation of emotional response, group discussion (thematic, biographical and interactive), brainstorming, game dramatization techniques, case studies, written self-reports). The program was implemented by means of the socio-psychological training. Early adolescence is the most favorable period for the development of empathic interpersonal interaction. The latter is provided by the purposeful psychological impact on the personal qualities and characteristics of an adolescent that contribute to the increase of the integrated empathy level (actualizing empathic attitude, development of decentration, anticipation, reflection, alterocentrism, etc.) on the one hand and the adolescents' awareness of the consequences of different types of empathic behavior, on the other. The basic results of approbation of the program are presented. The effectiveness of the development of empathic interpersonal interaction by means of group and individual psychological correction has been proved. The statistically significant changes in indicators of integrated empathy (their growth) as well as interrupted (decrease of the frequency of manifestations) and subjective-centered (increase of the frequency of manifestations) empathy interaction have been found. In the analysis of gender differences in male adolescents from the experimental group, some significant changes in indicators of altruistic interaction (increase of the frequency of its manifestations) have been noticed. The postponed effect of the program, which was manifested in the further reducing of the number of interrupted empathic interactions and the growing of altruistic ones, was observed.

Keywords: empathic interpersonal interaction, the program facilitating the development of empathic interpersonal interaction, socio-psychological training, formative experiment, adolescence.

Подано до редакиії 01.09.2016

УДК: 159.9

Елена Владимировна Костюнина, аспирант кафедры психологии развития и сочиальных коммуникаций, Южноукраинский национальный педагогический университет имени К. Д. Уиинского, ул. Фонтанская дорога, 4, г. Одесса, Украина

\section{ПРОФЕССИОНАЛЬНАЯ ИДЕНТИЧНОСТЬ ПЕДАГОГИЧЕСКИХ РАБОТНИКОВ РЕКРЕАЦИОННОГО УЧРЕЖДЕНИЯ: НОВЫЕ ВОЗМОЖНОСТИ ИССЛЕДОВАНИЯ}

Статья посвящена изучению новых возможностей и прогностической ценности исследования профессиональной идентичности педагогов-организаторов учреждений рекреащии. В статье представлен обзор существующих теоретических подходов к изучению профессиональной идентичности, профессиональной «Я-концепции». В основе идеи статьи лежит не обзор научных школ в рамках изучения профессиональной идентичности, а обобщение опьта, который был получен в ходе практической деятельности организаиии психологического сопровождения профессиональной адаптащии педагогов-организаторов рекреационного учреждения на базе УДЦ «Молодая гвардия».

Ключевые слова: профессиональная идентичность, педагог-организатор, рекреационное учреждение, дискурсивно-графический метод (ДГТ), образ профессии.

Современный уровень развития социальных отношений выдвигает особые требования к уровню профессионализма, «образу профессии» и результатам деятельности человека. Одной из ключевых тем общественного дискурса является обсуждение профессиональной «Я-концепции» педагогических ра- ботников, новые требования и ожидания социума от педагогического сообщества.

Особое место в когорте педагогических работников занимают педагоги-организаторы рекреационных учреждений. Неопределённость «образа профессии» (эволюция от «вожатого» до «педагога- 
организатора»), низкая статистическая значимость численности профессионального сообщества «педагогов-организаторов рекреационных учреждений» на фоне общей численности педагогических работников учебных заведений, высокая динамика изменения «образа» - эти факторы повлияли на формирование незаслуженно низкого рейтинга в научных исследованиях данной выборки. С другой стороны, именно сегодняшняя ситуация предопределяет высокую значимость профессионализма педагогов-организаторов рекреационных учреждений как профессионального сообщества, которое находится «на передовой» в рамках работы с группами детей, пережившими различные формы насилия, психологической травматизации, неуспешной социализации.

Исследование профессиональной идентичности педагогов-организаторов рекреационного учреждения на базе УДЦ «Молодая гвардия» дает нам уникальную возможность не только получить многогранное представление о личности педагога-организатора, его профессиональной «Я-концепции», а также изучить психологические условия формирования и поддержания позитивной профессиональной идентичности, что, в свою очередь, влияет на успешность деятельности и возможности развития профессиональной карьеры.

В этой связи актуальными для нашего исследования становятся вопросы самоопределения и самоактуализации личности, «Я-концепции» профессиональной идентичности. Тема личностного самоопределения и личной идентичности входит в круг научных интересов многих исследователей. Особый интерес для нашей исследовательской позиции представляют работы Б. Г. Ананьева, К. А. АльбухановойСлавской, С. Л. Рубинштейна, Б. Ф. Ломова, А. В. Брушлинского, А. В. Петровского, В. И. Слободчикова, Л. А. Регуш, А. Маслоу, В. Франкла и др.

Концепцию самоопределения невозможно рассматривать вне понятия идентичности, введенного Э. Эриксоном. По его определению, идентичность это «тождественность человека самому себе (неизменность личности в пространстве) и целостность (преемственность личности во времени)» [7].

Важным компонентом развития личностной идентичности есть развитие профессиональной идентичности. Исследователи представляют различные определения профессиональной идентичности. Так, например, Л. Б. Шнайдер акцентирует внимание на центральном механизме профессиональной идентичности - осознании - «психологической категории, относящейся к осознанию своей принадлежности к определенной профессии и определенному профессиональному сообществу» [6]. Ю. П. Поваренков использует понятие «принятие ценностей» и описывает профессиональную идентичность как «принятие индивидуумом на социальном и психологическом уровнях профессиональных ценностных позиций, нормативных для данного профессионального простран- ства». Е. П. Ермолаева обсуждает профессиональную идентичность как системную характеристику социально-деятельностного соответствия с фокусом на триаде понятий «человек - профессия - общество». Н. С. Пряжников указывает на неразрывную связь профессионального самоопределения с самореализацией человека в других сферах жизни. Системный взгляд на профессиональную «Я-концепцию» отражает в своих работах С. Т. Джанерьян. «Я-концепция» в ее представлении - это «система сопряженных с оценкой представлений человека о себе как субъекте профессиональной деятельности и как личности, предназначенная для реализации тех или иных по содержанию смысловых отношений человека к профессии и через это для обеспечения его собственного функционирования и/или развития и самореализации в профессии» [3]. Для понимания профессиональной идентичности как активности важно обратится к работам Б. Ф. Ломова о психологической природе деятельности. Е. А. Климов неоднократно подчеркивал, что профессиональное самоопределение несводимо к одноминутному акту выбора профессии, это длительный процесс, начало которому положено в онтогенетической истории человека и длительностью всю профессиональную жизнь. По его мнению, профессиональное самоопределение происходит по формуле: «Мгновение плюс вся предшествующая жизнь».

Исходя из осуществленного анализа, возможно резюмировать, что процесс приобретения профессиональной идентичности является важным, длительным, многоуровневым, мульти-критериальным. При этом, в силу своей латентности, этот процесс представляется неоднозначным и скрытым для изучения и прямого наблюдения.

В современной отечественной и зарубежной психодиагностике накоплен достаточный пул методов, позволяющих определять профессиональную направленность, готовность к определенной профессиональной деятельности. Но мы можем констатировать недостаточность количества методик, позволяющих определить динамику становления профессиональной идентичности, влияние различных личностных факторов и условий на этот процесс.

В целях восполнения существующего пробела нами был разработан оригинальный дискурсивнографический тест (ДГТ), который позволяет не только выявить актуальный статус профессиональной идентичности педагога-организатора рекреационного учреждения, но и исследовать причины, мотивы возникновения того или иного статуса (когнитивного, эмоционального, личностного).

Целью работы является изучение возможностей ДГТ в исследовании профессиональной идентичности педагога-организатора рекреационного учреждения как относительно устойчивой системы динамических взаимосвязанных процессов, протекающих на различных личностных уровнях и организованных на основе потребностей, эмоций и индивидуального опыта. 
Психодиагностический комплекс исследования разработан в рамках «качественной парадигмы» и состоит из нескольких методик, которые проводились поэтапно. Были применены следующие методы: нарративный метод в формате выполнения упражнений «Ищу идеального вожатого» и упражнения с элементами шкалирования «Образ профессии: успешный педагог - организатор УДЦ «Молодая гвардия»; метод экспертной оценки и тестирование методом ДГТ.

Исследование проводилось на базе Всеукраинского рекреационного центра УДЦ «Молодая гвардия» г. Одесса. В исследовании принимали участие 236 респондентов, из них: 95 - педагоги-организаторы трех лагерей УДЦ «Молодая гвардия»; 127 респондентов - школьники-рекреанты и 14 человек экспертной группы в следующем составе: начальники лагерей, заместители начальника лагеря по воспитатель- ной работе, методисты научно-методического отдела и практические психологи кафедры психологии развития и социальных коммуникаций ЮНПУ имени К. Д. Ушинского.

На первом этапе, детям-рекреантам было предложено выполнить упражнение «Ищу идеального вожатого», целью которого мы обозначили формирование и обсуждение портрета идеального вожатого детского центра «Молодая гвардия». В игровой форме была поставлена задача: придумать и подготовить на листе объявление на тему «Ищу идеального вожатого», в котором необходимо описать, какими качествами, с их точки зрения, должен обладать идеальный вожатый. После проведения дебрифинга получен профиль «идеального вожатого» и статистическая значимость предпочтительного выбора этих качеств для группы «дети-рекреанты» (рис.1).

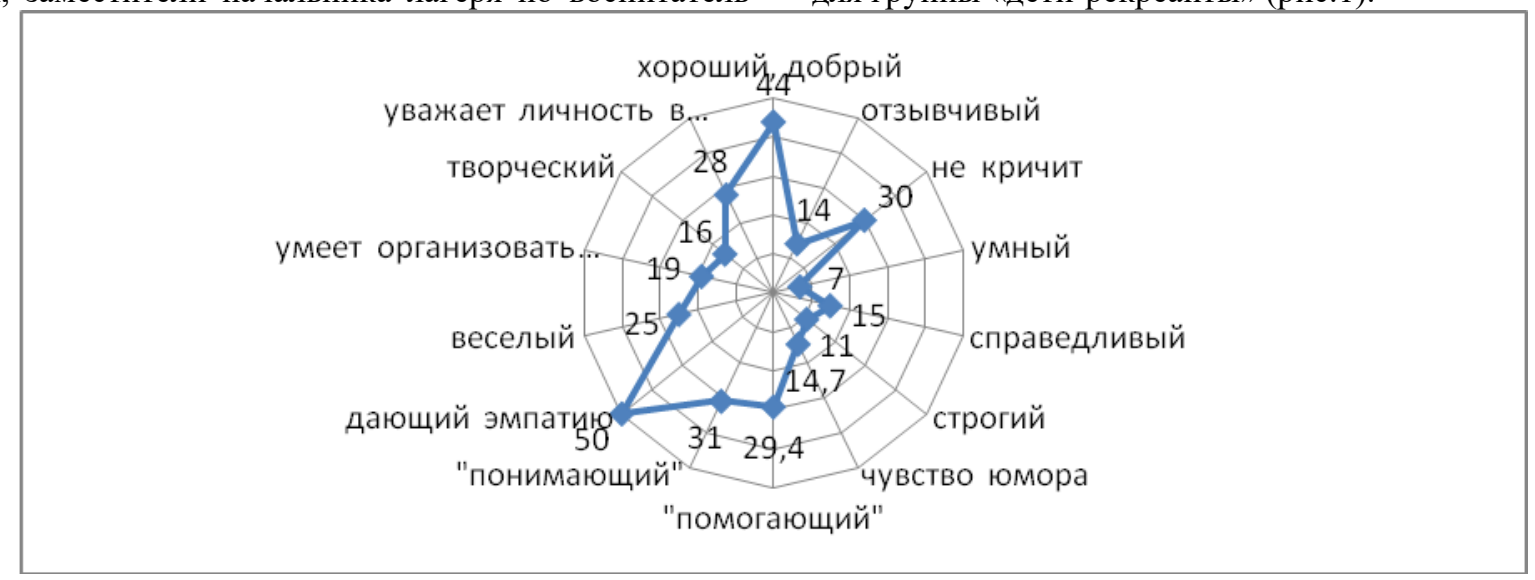

Рис. 1. Профиль «идеального вожатого» и статистическая значимость этих качеств для группь «дети-рекреанты»

Для изучения самоотношения к своей профессиональной роли, а также для обсуждения «образа профессии» и в рамках него профессиональной «Яконцепции» педагогам-организаторам было предложено выполнить упражнение «Образ профессии: успешный педагог-организатор УДЦ «Молодая гвардия». Общее количество участников упражнения составило 95 респондентов. Упражнение проводилось в группах по 12-15 человек и выполнялось в несколько этапов в рамках одного тренингового занятия.

Для начала участники индивидуально составили перечень качеств, которыми, по их мнению, должен обладать идеальный педагог-организатор УДЦ «Молодая гвардия». Далее, после готовности индивидуальных списков, на основании свободного выбора были сформированы рабочие группы по 5 человек. Задачей групп было составить согласованный групповой список качеств «идеального педагогаорганизатора УДЦ «Молодая гвардия» и выставить выраженность каждого качества по шкале в 100 баллов (самый низкий балл - 0, самый высокий - 100).
При составлении списка необходимо было учитывать мнение каждого участника группы. Тайминг второго этапа - 10 минут. На третьем этапе докладчики, выбранные в группе, презентовали перечень качеств, выработанный группой, а далее проводилось обсуждение в большой группе.

Итогом совместной работы группы стал психографический профиль успешного педагогаорганизатора УДЦ «Молодая гвардия» (рис.2.).

Следующий этап исследования был проведен методом экспертных оценок. Профессиональный уровень педагогов-организаторов рекреационного учреждения может быть оценен только экспертами, которые хорошо понимают особенности и специфику работы в УДЦ «Молодая гвардия». Исходя из этого, в группу экспертов вошли начальники лагерей, заместители начальника лагеря по воспитательной работе, методисты научнометодического отдела и практические психологи кафедры психологии развития и социальных коммуникаций ЮНПУ имени К. Д. Ушинского. 


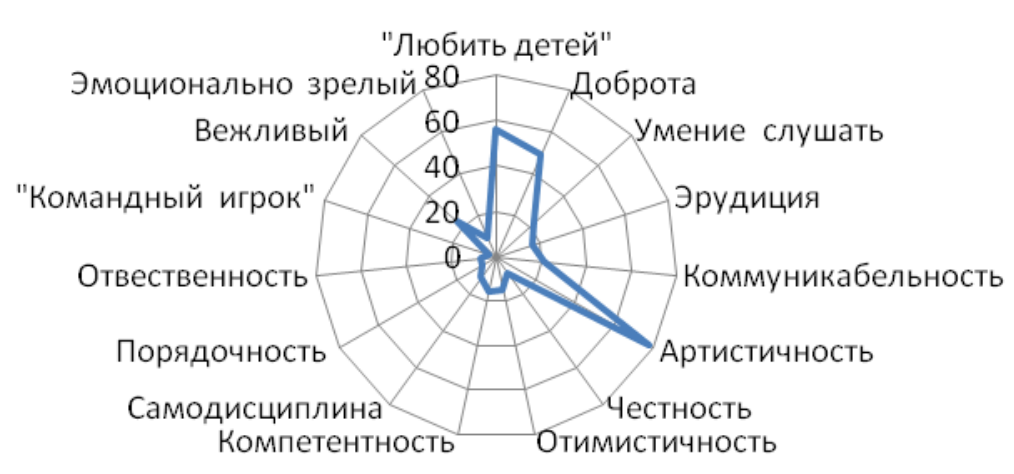

Рис. 2. Психографический профиль успешного педагога-организатора УДЦ «Молодая гвардия»

На этом этапе были получены следующие данные: фамилии пяти самых успешных педагоговорганизаторов (отдельно по каждому лагерю; всего 15 человек), работающих в УДЦ «Молодая гвардия» более одного года; фамилии пяти самых «неуспешных» педагогов-организаторов (отдельно по каждому лагерю; всего - 15 человек), работающих в УДЦ «Молодая гвардия» более одного года; ранжированный список с оценкой успешности (по 4-х балльной шкале) остальных 65 человек (также отдельно по каждому лагерю).

Следующий этап исследования был организован следующим образом. По результатам предыдущего этапа исследования нарративным методом был построен «образ профессии» (представление о своей профессии) каждого респондента, т. е. определен нормативный уровень выраженности психофизиологических свойств для данной профессии, с их точки зрения. В результате мы получили идеальный профиль профессии «педагог-организатор рекреационного учреждения» и 95 «профилей-образов» педагоговорганизаторов, участвующих в эксперименте. Используя метод оценки адекватности кривых, мы определили соответствие «образа профессии» каждого педагога-организатора идеальному профилю, т. е. мы получили ранжированный список респондентов с точки зрения успешности их деятельности.

Далее для нас представляло исследовательский интерес провести корреляционный анализ с использованием методов непараметрической статистики для того, чтобы получить представление о степени корреляции трех профилей: дети - педагоги-организаторы экспертная группа. рис.3.

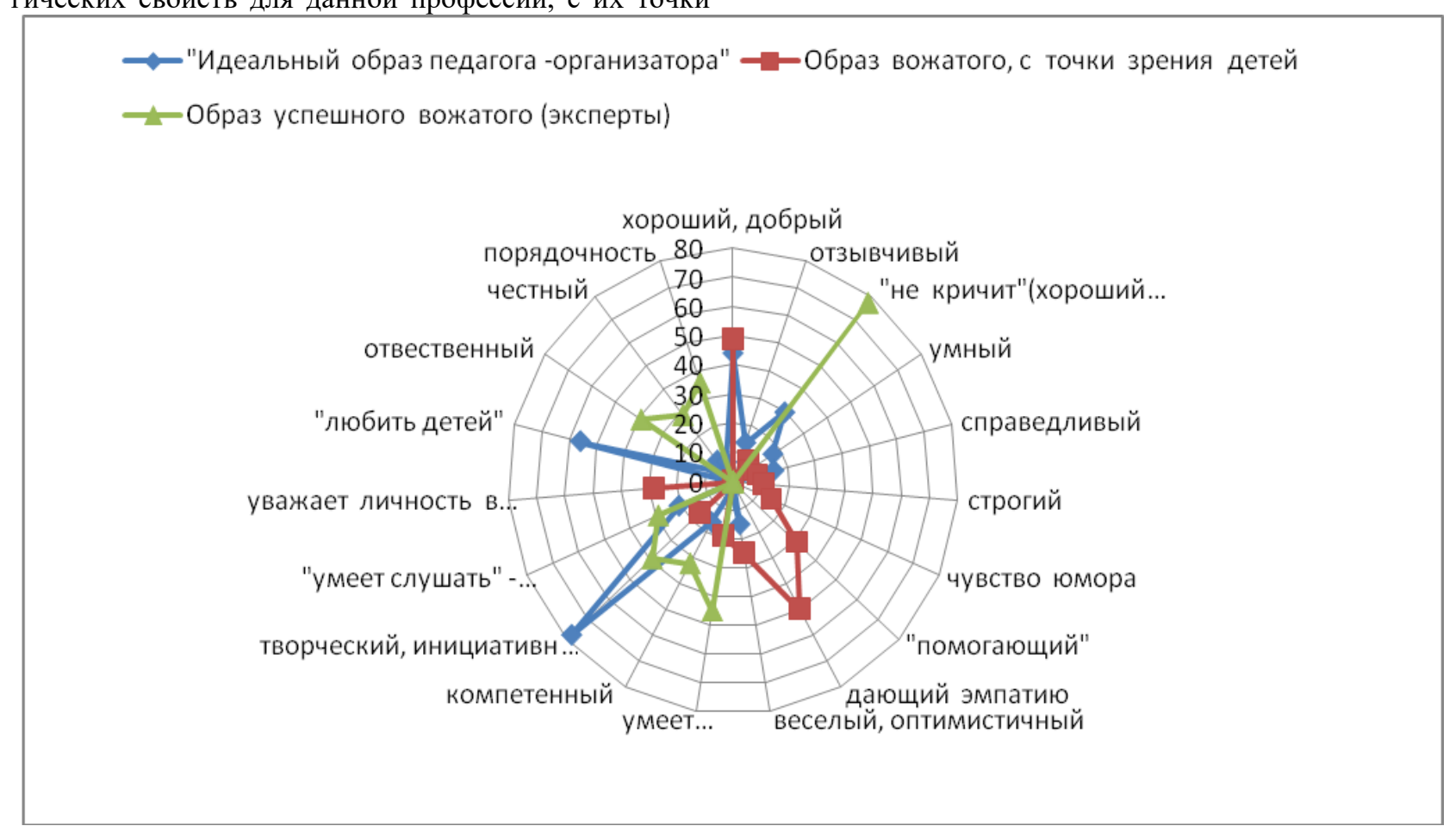

Рис. 3. Степень коррелящии трех профилей: «дети - педагоги -организаторь - экспертная группа». 
Анализируя полученные данные, мы наглядно видим несоответствие в представлении об «идеальном образе профессии» в группах выборки: «педагогиорганизаторы», «дети-рекреанты» и «эксперты».

Акцент «идеального образа вожатого», который разработали школьники-рекреанты, делается на эмоциональную эмпатийную поддержку (понимающий, помогающий, поддерживающий и пр.), у педагоговорганизаторов превалируют личные творческие предпочтения и определение образа профессии на бытовом уровне (добрый, хороший, люблю детей и пр.), группа экспертов рассматривает образ профессии «педагог-организатор» в фокусе организационной психологии и администрирования (дисциплинированный, ответственный, компетентный).

Все три категории единодушны в ценности таких качеств: творческий потенциал, хороший контроль эмоций.

Учитывая данные, полученные нами ранее, можно вычленить задачи для дальнейших исследований, и, в первую очередь, задача разработки психографического профиля педагога-организатора рекреационного учреждения, включающего в себя ожидания всех субъектов поля профессиональной коммуникации.

Следующий этап исследования был организован следующим образом. Для того, чтобы исследовать свозь призму профессиональной идентичности процессы, протекающие на различных личностных уровнях и организованные на основе потребностей, эмоций и индивидуального опыта, был разработан дискурсивно-графический тест (ДГТ).

Целью разработки является подтверждение исследовательской гипотезы о том, что сочетание стимульных знаков при выполнении задания простым карандашом дают нам картину когнитивной дифференцированности образа профессии педагогаорганизатора, характер самопрезентации; и в то же время сочетание стимульных знаков при выполнении задания цветными карандашами позволяет нам провести анализ эмоционального самоотношения, исследовать эмоционально-оценочный критерий, к которому относим уровень самоотношения, самоощущения и поведенческий критерий, включающий в себя степень психологической готовности, эмоциональную зрелость, профессиональную направленность, уровень притязаний, характер объектных отношений.

При разработке метода мы опирались, в частности, на научные разработки Н. К. Рауш де Траубенберг «Тест Роршаха», исследования В. К. Калиненко [5], работы A. Krissi [10] в области валидизации и практического применения рисуночного теста Вартегга (Wartegg-Zeichen-Test (WZT), исследования C. Т. Джанерьян о профессиональной Я-концепции; научную работу В. П. Серкина «Структура и функции образа мира в практической деятельности»; исследовательские идеи П. В. Яньшина в работе «Цветосоциометрия как метод социальной психологии» [8] и др.

Тест ДГТ разработан как расширенная модификация Wartegg-Zeichen-Test (WZT) [5; 9] с включением цветовой символической структуры, соотнесенной с эмоционально-личностными особенностями респондента. Дискурсивным полем является символические артефакты Wartegg-Zeichen-Test (WZT). Цветовое решение является «самостоятельной системой ориентации в действительности, причем такой системой, которая способна осуществлять комплексное изменение функционального состояния индивида, минуя сознание, а также точно сигнализировать об этом изменении» [8]. S. J. Gronnerod [9] в 2012 году опубликовал данные мета-анализа 37 исследований теста WZT, проведенных с использованием различных скоринговых систем. В них определен коэффициент валидности WZT $=0,33$, что сопоставимо со статистической значимостью тестов MMPI-2, Rorschachи WAIS.

Тест выполнялся с использованием стимульного материала Wartegg-Zeichen-Test (WZT) [10] без изменения инструкции, в двух сериях. Первая серия выполняется простым карандашом (рис 4). Вторая цветными карандашами (рис 5).

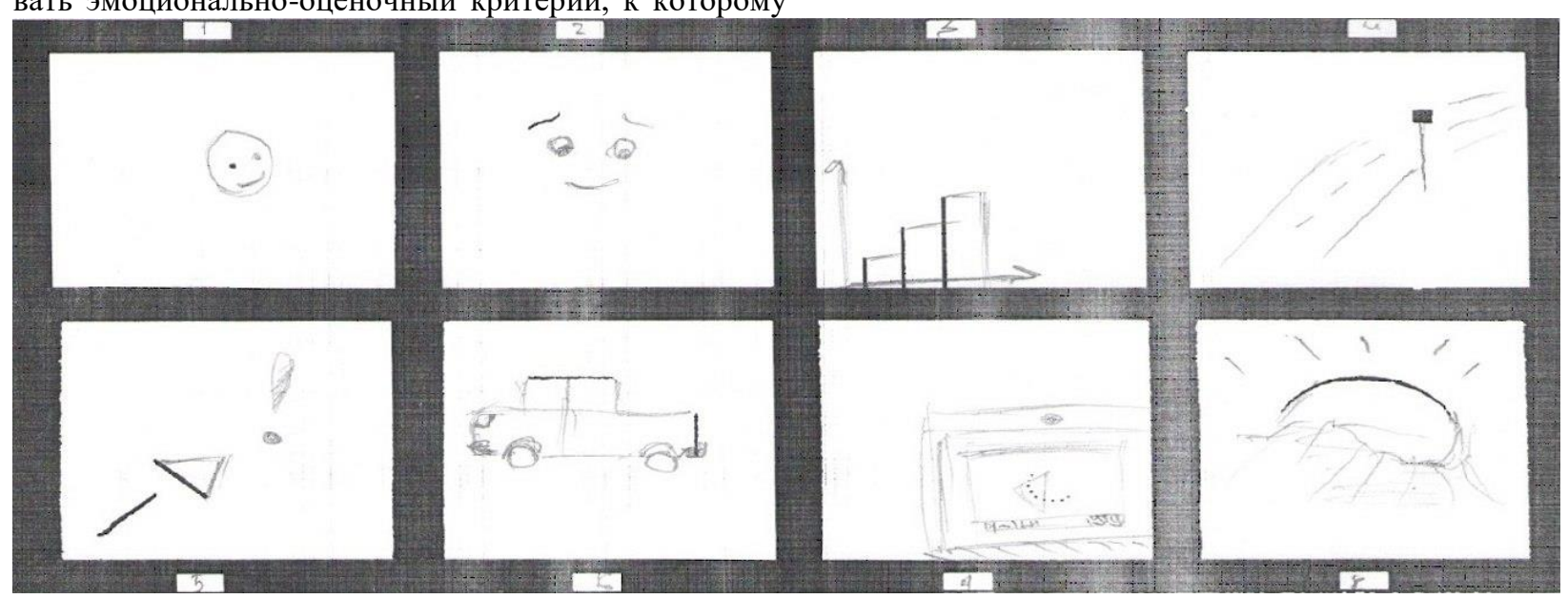

Рис. 4 Респондент Р. Первая серия теста ДГТ. 


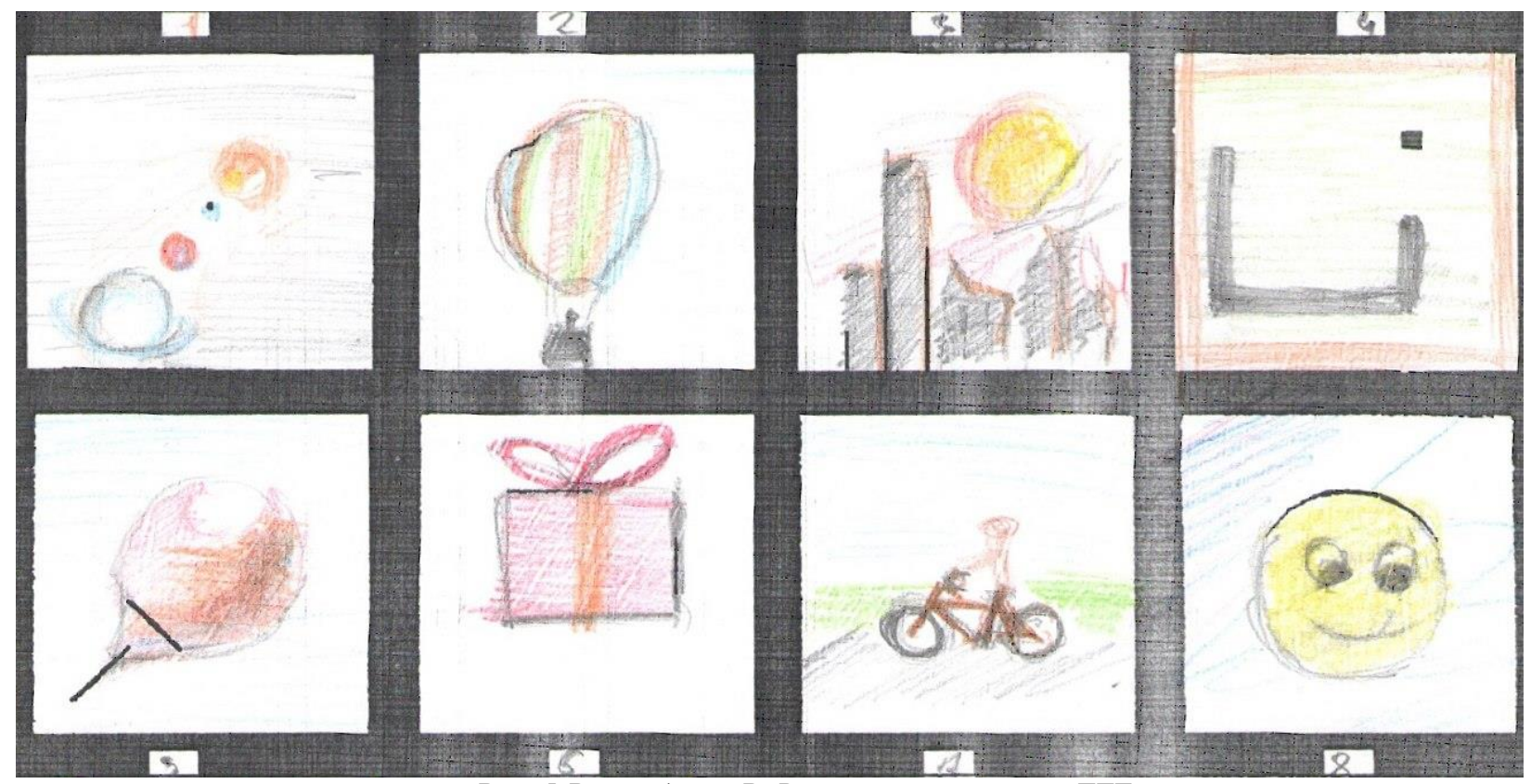

Рис. 5 Респондент Р. Вторая серия теста ДГТ

После того, как задание выполнено, было проведено индивидуальное интервью с респондентами по каждой серии с целью определения личных смыслов и эмоциональной нагруженности на предложенные символы, оценки эмоционального отношения с применением таких критериев: «приятные - неприятные» квадраты, «стимулы, в которых реализация соответствовала замыслу» и «стимулы, в которых реализация не соответствовала замыслу», кроме того, зафиксированы свободные комментарии респондентов.

Обработка протоколов ДГТ. На начальном этапе дифференцировали протоколы с высоким процентом «минусовых» критериев, что позволило нам выделить респондентов с «профилем травмы», невротическими проявлениями. Следующим шагом было составление индивидуального уровневого профиля респондента и описание его особенностей (соответствует ли нормативному, есть ли переходы на другой уровень, анализ позитивных и негативных выборов). После - оценили согласованность двух рисуночных композиций и выявили процентную долю позитивных оригинальных мотивов. Далее провели сигнификацию стимульных знаков при выполнении задания простым карандашом и затем повторно ту же процедуру с протоколом, выполненным цветными карандашами. На заключительном этапе обработки проведен анализ семантического поля, в том числе, анализ эмоционального самоотношения, который включает в себя эмоциональнооценочный критерий, к которому относим уровень самоотношения и самоощущения; поведенческий критерий, который включает в себя степень психологической готовности, эмоциональную зрелость, профессиональную направленность, уровень притязаний, характер объектных отношений. Составляем индивидуальный характерологический профиль (сравнитель- ная диаграмма когнитивного и эмоционального компонента характерологического профиля).

Обработка результатов исследования может проводиться как в полном объеме, так и в формате «экспресс».

Обсуждение результатов.

После обработки протоколов нашего исследования были получены следующие данные.

Выборка «успешные педагоги-организаторы».

Во-первых, респонденты данной выборки во время выполнения задания заполняли бланки нормативно, без изменения последовательности и не переходили на другой уровень. Данный показатель интерпретируется как «полезависимость» и говорит о том, что респонденты этой выборки хорошо осознают внешние правила и следуют им, способны контролировать эмоции и поведение, хорошо осознают требования реальности.

Во-вторых, распределение качественных критериев амбивалентно и выглядит следующим образом (Табл.1.): как «наиболее комфортные» выделены сферы личной идентичности, самооценки, самоотношения, способность создавать целостность, не застревать в расщепленном состоянии и статус «Я-социальное». Кроме того, респонденты не испытывают чувства тревоги при выстраивании отношений с другими людьми, внешним миром, у них выработаны стратегии решения конфликтов и высокая фрустрационная толерантность. Респонденты способны действовать при требованиях максимальной эффективности (работоспособность.) С другой стороны, они испытывают сложности в сфере «Я-переживаний» (Я-концепция, включающая профессиональную Я-концепцию), неуверены в оценке объектных отношений в ближайшем окружении. 
Таблица 1.

Распределения качественных критериев среди выборки «успешные педагоги-организаторы».

\begin{tabular}{|c|c|c|}
\hline Критерии & $\begin{array}{c}\text { Первая серия } \\
\text { (использовали простой } \\
\text { карандаш) }\end{array}$ & $\begin{array}{c}\text { Вторая серия } \\
\text { (использовали цвет- } \\
\text { ные карандаши) }\end{array}$ \\
\hline «приятные» выборы & 6,8 & $1,6,8$ \\
\hline «неприятные» выборы & $1,3,6,7$ & 2,3 \\
\hline стимулы, в которых реализация соответствовала замыслу & $2,3,4,5$ & 2,5 \\
\hline стимулы, в которых реализация не соответствовала замыслу & 1,6 & $4,5,8$ \\
\hline
\end{tabular}

Типичными признаками, выявленными в данной группе, являются: содержание рисунков нормативное, необеднённое; богатый эмоциональный визуальный ряд; оригинальные, творческие решения; хороший контроль импульсов; эмоции не изолируются, а находят социально приемлемое выражение, в том числе, через реализацию в профессии педагог-организатор;

Выборка «неуспешные» педагоги-организаторы.

В 38\% случаев респонденты заполняли бланк с переходом на другой уровень, что является «неблагополучным критерием»; 19\% показали «минусовые» критерии стимулов №4,5 (показатель травматизации и неудачной адаптации, высокий уровень напряжения в рамках триады «страх - вина - тревога»); в 23\% случаев наблюдается игнорирование стимулов, что говорит о сложностях в определенных сферах бессозна- тельного; 34\% презентуют картину «изоляция аффекта»; у 23\% нарушен контроль импульсов; 16 \% находятся на стадии регресса (фаза «каракулей»); 9\% находятся в стадии невротического реагирования.

Анализируя данные, представленные в таблице 2, мы наблюдаем также амбивалентность показателей, а общий тренд направлен в сторону отрицательных критериев. Отмечаем аспекты психотравмы, посттравматические выходы, актуальные для человека в момент тестирования; «Я-социальное» ослаблено, отсутствует ощущение защищенности, механизм внутренней адаптации нарушен. При выполнении второй серии явно заметно увеличение степени напряженности в сфере переживания «страх - вина тревога».

Таблица 2.

Распределение качественных критериев среди выборки «неуспешные педагоги-организаторы».

\begin{tabular}{|c|c|c|}
\hline Критерии & $\begin{array}{c}\text { Первая серия } \\
\text { (использовали про- } \\
\text { стой карандаш) }\end{array}$ & $\begin{array}{c}\text { Вторая серия } \\
\text { (использовали цвет- } \\
\text { ные карандаши) }\end{array}$ \\
\hline «приятные» выборы & $1,2,7,6$ & $1,2,8 ;$ \\
\hline «неприятные» выборы & $4,5,8$ & 7,$8 ;$ \\
\hline стимулы, в которых реализация соответствовала замыслу & $4,5,8$ & 5,$6 ;$ \\
\hline стимулы, в которых реализация не соответствовала замыслу & 3,4 & 7,5 \\
\hline
\end{tabular}

Типичными признаками, выявленными в данной группе, являются плохой контроль импульсов, персеверации, атипии, изоляция эмоций, стереотипии. Эти показатели свидетельствуют о высоком уровне внутреннего напряжения и противоположны состоянию внутренней свободы, творческого самовыражения.

В рамках этой статьи мы не будем размышлять над вопросом, который логично вытекает из полученных результатов: было ли это актуальное состояние респондентов в момент найма на работу, либо это характеризует состояние неудачной профессиональной адаптации, неуспешной профессиональной идентичности, или первое определяет второе. Важным в данной ситуации есть понимание, что с помощью метода ДГТ, во-первых, мы можем фиксировать данное состояние, во-вторых, имеем возможность выработать стратегии психологического сопровождения респондента либо в рамках консультации профессио- нальной ориентации, либо профессиональной адаптации.

Полученные данные при применении дискурсивно-графического теста (ДГТ) дают хороший прогноз для практического использования его как в качестве дополнительной методики для проведения комплексных исследований, так и для проведения самостоятельной экспресс-диагностики состояния профессиональной идентичности как сумме психологических представлений и самоотношения к образу «Япрофессионал». Проведенное исследование показало, что ДГТ может быть практически использован для прогноза успешности в профессии «педагогорганизатор учреждений рекреации», определения психологической и эмоциональной готовности, состояния профессиональной идентичности на основании интерпретации соотношения качественных критериев дискурсивно-графического теста (ДГТ). 


\section{ЛИТЕРАТУРА}

1. Бурлачук Л. Ф. Психодиагностика / Л. Ф. Бурлачук. - СПб. : Питер, 2002. - 352 с.

2. Вигдорчик М. И. Компьютерная автоматизированная психодиагностическая программа «КОНСУЛ-4» / М. И. Вигдорчик, М. Е. Вигдорчик, Э. М. Псядло и др. - Одесса: Информ. листок ОЦНТЭИ, 1997. - №172. - 97 с.

3. Джанерьян С. Т. Системный подход к изучению профессиональной Я-концепции // С. Т. Джанерьян // Вестник ОГУ. - 2005. - №4. - С. 28-29.

4. Зинченко Т. П. Автоматизированная система профессиональной диагностики / Т. П. Зинченко, А. А. Фрумкин, Е. В. Горбунова // Психологические исследования. - Вып.1. - СПб. - 1997. - С. 42-43.

5. Калиненко В. К. Рисуночный тест Вартегга: практическое руководство / В. К. Калиненко. - М. : Смысл, 2013. - 239 с.

6. Шнейдер Л. Б. Профессиональная идентич-

\section{REFERENCES}

1. Burlachuk, L. F. (2002). Psikhodiagnostika [Psychodiagnostics]. Saint Petersburg: Piter [in Russian].

2. Vigdorchik, M. I., Vigdorchik, M. E., Psyadlo, E. M. (1997). Kompyuternaya avtomatizirovannaya psikhodiagnosticheskaya programma «KONSUL-4» [Computer automatized psychodiagnostic program "Konsul-4”]. Odessa: Inform. listok OTsNTEI [in Russian].

3. Dzhaneryan, S. T. (2005). Sistemnyy podkhod k izucheniyu professionalnoy Ya-kontseptsii [System approach to studying professional self-concept]. Vestnik $O G U$ - Bulletin of $O S U, 4,28-29$ [in Russian].

4. Zinchenko, T. P., Frumkin, A. A., Gorbunova, E. V. (1997). Avtomatizirovannaya sistema professionalnoy diagnostiki [Automatized system of professional diagnostics]. Psikhologicheskie issledovaniya - Psychological studies, 1, 42-43. Saint Petersburg [in Russian].

5. Kalinenko, V. K. (2013). Risunochnyy test Vartegga: prakticheskoe rukovodstvo [Wartegg drawing test: manual]. Moscow: Smysl [in Russian].

6. Shneyder, L. B. (2004). Professionalnaya identichnost: teoriya, eksperiment, trening: ucheb. posobie ность: теория, эксперимент, тренинг: учеб. пособие / Л. Б. Шнайдер. - М.: Издательство Московского психолого-социального института; Воронеж: Издательство НПО «МОДЭК», 2004. - 600 с.

7.Эриксон Э. Идентичность: юность и кризис / Э. Эриксон / Пер. с англ. - М. : Флинта, 2006. - 342 с.

8. Яньшин П. В. Цвето-социометрия как метод социальной психологии: Учебно-методическое пособие / П. В. Яньшин. - Самара: Изд-во СамГПУ, 2002. $-85 \mathrm{c}$.

9.Gronnerod S. J. The Wartegg Zeichen Test: A literature Overview and a Meta-Analysis of Reliability and Validity / S. J. Gronnerod, C. Gronnerod // Psychological Assessment. - 24. - 2012. - P. 476-489.

10.Crisi A. The Wartegg Drawing Completion Test: Inter-rater Agreement and Criterion Validity / A. Crisi // International Journal of Psychology and Psychological Therapy. $-2016 .-90$ p.

[Professional identity: theory, experiment, training: textbook]. Moscow: Izdatelstvo Moskovskogo psikhologosotsialnogo instituta; Voronezh: Izdatelstvo NPO «MODEK» [in Russian].

7. Erikson, E. (2006). Identichnost: yunost $i$ krizis [Identity: youth and crisis]. Moscow: Flinta [in Russian].

8. Yanshin, P. V. (2002). Tsveto-sotsiometriya kak metod sotsialnoy psikhologii: uchebno-metodicheskoe posobie [Colour sotsionometrics as a methods of social psychology: study guide]. Samara: Izd-vo SamGPU [in Russian].

9. Gronnerod, S. J., Gronnerod, C. (2012). The Wartegg Zeichen Test: A literature Overview and a MetaAnalysis of Reliability and Validity. Psychological Assessment, 24, 476-489 [in English].

10. Crisi, A. (2016). The Wartegg Drawing Completion Test: Inter-rater Agreement and Criterion Validity. International Journal of Psychology and Psychological Therapy [in English].

\section{Південноукраӥнський національний педагогічний університет імені К. Д. Уиинського, \\ ПРОФЕСІЙНА ІДЕНТИЧНІСТЬ ПЕДАГОГІЧНИХ ПРАЦІВНИКІВ РЕКРЕАЦІЙНОӤ УСТАНОВИ: НОВІ МОЖЛИВОСТІ ДОСЛІДЖЕННЯ}

Олена Володимирівна Костюніна, аспірант кафедри психології розвитку і соиіальних комунікацій, вул. Фонтанська дорога, 4, м. Одеса, Украӥна

Статтю присвячено вивченню нових можливостей та прогностичної цінності дослідження професійної ідентичності педагогів-організаторів установ рекреації. У роботі представлено огляд існуючих теоретичних підходів до вивчення професійної ідентичності, професійної «Я-концепції». Також показано, що проблема професійної ідентифікації педагога-організатора ускладнюється відсутністю цілісного «образу професії» та надійного критерію для визначення «успішного педагога-організатора установи рекреації». Обговорюються психологічні умови трансформації статусу професійної ідентичності. Різні форми професійної ідентичності у взаємозв'язку з соціальними викликами і завданнями вимагають нових методів вивчення. Особлива увага приділяється особливостям наративного, дискурсивного та проективного підходів, що дозволяють вважати ці методи одними 3 
пріоритетних напрямків вивчення професійної ідентичності педагогів-організаторів рекреаційної установи. У статті описується оригінальний діагностичний метод - дискурсивно-графічний тест (ДГТ). Під час розробки методики ми спиралися на наукові ідеї Н. К. Рауш де Траубенберг, В. К. Каліненко, А. Сrisi у фокусі валідізації і практичного застосування графічного тесту Вартегга (Wartegg Zeichen-Test), дослідження С. Т. Джанерьян, В. П. Серкіна, П. В. Яньшина і ін. Тест ДГТ розроблено нами як розширену модифікацію Wartegg Zeichen-Test (WZT) із включенням кольорово-символічної структури, співвіднесеної з емоційно-особистісними особливостями респондентів. Дискурсивно-графічний тест (ДГТ) дозволив у рамках дослідження вивчити стан респондентів на рівні когнітивної презентації, описати характер самопрезентації і в той же час провести аналіз емоційного самоставлення, самовідчуття, ступінь психологічної готовності, рівня емоційної зрілості, вектор професійної спрямованості, рівень домагань, характер об'єктних відносин. Проведене дослідження показало, що дискурсивно-графічний тест (ДГТ) може бути застосований як для прогнозу успішності в професії «педагог-організатор установ рекреації», так і для визначення ступеня психологічної та емоційної зрілості, стану професійної ідентичності. Крім того, метод має потужний потенціал при визначенні актуального психоемоційного стану особистості. В основі ідеї статті покладено не огляд наукових шкіл із питань вивчення професійної ідентичності, а узагальнення досвіду, який було отримано під час практичної діяльності організації психологічного супроводу професіональної адаптації педагогів-організаторів рекреаційної установи на базі Всеукраїнського рекреаційного центру «Молода гвардія».

Ключові слова: професійна ідентичність, педагог-організатор, рекреаційна установа, дискурсивнографічний метод (ДГТ), образ професіі.

\author{
Olena Kostiunina, \\ post-graduate student, \\ Department of Developmental Psychology and Social Communications, \\ South Ukrainian National Pedagogical University named after K. D. Ushynsky, \\ 4, Fontanska Doroha Str., Odesa, Ukraine
}

\title{
PROFESSIONAL IDENTITY OF RECREATIONAL INSTITUTION EDUCATORS: NEW RESEARCH OPPORTUNITIES
}

The article deals with the study of new opportunities and prognostic value of professional identity of educators working at recreational institutions. The issue of professional identity of an educator is complicated by the absence of the integral "professional image" and criterion for determining the concept "successful educator of a recreational institution". Different forms of professional identity together with social challenges and tasks require new methods of research. Special attention is paid to the peculiarities of narrative, discursive and projective approaches, which make it possible to consider these methods as one of the most preferred directions of studying the issue of professional identity of recreational institution educators. The original diagnostic method - discursive graphic test (DGT) - has been described in the paper. When developing this technique, the scientific ideas of N. Rauch de Traubenberg, V. Kalinenko, A. Crisi in the area of validation and practical use of The Wartegg Zeichen Test, studies of S. Dzhaneryan, V. Serkin, P. Yanshin were taken into account. The DGT was developed as an extended modification of The Wartegg Zeichen Test with the adding of colour and symbol structure, correlated with personal emotional characteristics of respondents. The DGT has made it possible to examine the respondents' state at the level of cognitive presentation, to describe the character of self-presentation and at the same time to analyze emotional self-attitude, sense of self, the level of psychological readiness, emotional maturity level, professional orientation, etc. It has been concluded that the DGT can be used for predicting the success in the job of a recreational institution educator, as well as for determining the level of psychological and emotional maturity, the state of professional identity. Besides, the developed technique can be used for examining individual's real psychoemotional state. The approbation of the DGT was carried out at "Moloda Hvardiia" Ukrainian recreational centre.

Keywords: professional identity, educator, recreational institution, discursive and graphic technique, vision of a profession.

Подано до редакиії 01.09.2016 